OPEN ACCESS

Edited by:

Stefano Spiezia,

Local Health Authority Naples 1

Center, Italy

Reviewed by:

Pietro Giorgio Calo',

University of Cagliari, Italy

Erivelto Martinho Volpi,

Centro de referencia no ensino do diagnóstico por imagem (CETRUS),

Brazil

${ }^{*}$ Correspondence: Sara Mazzone sara.mazzone1@gmail.com

Specialty section: This article was submitted to

Thyroid Endocrinology,

a section of the journal

Frontiers in Endocrinology

Received: 25 May 2021

Accepted: 02 July 2021

Published: 03 August 2021

Citation:

Mazzone S, Esposito A and Giacomarra V (2021) Continuous Intraoperative Nerve Monitoring in

Thyroid Surgery: Can Amplitude Be a Standardized Parameter?

Front. Endocrinol. 12:714699. doi: 10.3389/fendo.2021.714699

\section{Continuous Intraoperative Nerve Monitoring in Thyroid Surgery: Can Amplitude Be a Standardized Parameter?}

\author{
Sara Mazzone ${ }^{*}$, Adelaide Esposito and Vittorio Giacomarra \\ ENT Department, Santa Maria degli Angeli General Hospital, Pordenone, Italy
}

The objective of this study is to evaluate electromyographic waveforms related to vagus monitoring. We collected data from patients undergoing thyroidectomy with CIONM, regardless of vocal cord response amplitude initially measured. We divided data of 193 nerves into three groups, according to initial amplitude value: $\geq 500 \mu \mathrm{V}$ (Group 1,110 pt.), between 100 and $500 \mu \mathrm{V}$ (Group 2, 79 pt.), and <100 $\mu \mathrm{V}$ (Group 3, 4 pt.). ROC curve showed a high diagnostic accuracy of final amplitude absolute value in vocal cord paralysis detection in both groups (89 and 86\%). An increase of vocal cord paralysis risk was associated with progressive amplitude reduction (Group 1: $\mathrm{OR}=1.05, \mathrm{Cl}=1.02-$ 1.09, $\mathrm{p}=0.001$; Group 2: $\mathrm{OR}=1.05, \mathrm{Cl}=1.02-1.08, \mathrm{p}=0.002)$. Cut-off values for amplitude reduction with optimal sensitivity and specificity were $-77 \%$ in Group 1 and $-15 \%$ in Group 2. In Group 3 signals showed an amplitude $<100 \mu \mathrm{V}$ for all monitoring, with no loss of a recognizable signal and normal postoperative cordal functionality. The use of a strict amplitude signal cut-off value $\geq 500 \mu \mathrm{V}$ could be too restrictive. Also, signal with baseline amplitude $<500 \mu \mathrm{V}$ may be considered equally adequate. Setting the alarm for a reduction of $77 \%$ in patients with initial amplitude $\geq 500 \mu \mathrm{V}$ and of $15 \%$ for those $<500 \mu \mathrm{V}$ could make monitoring safe and an effective aid for surgeons. In conclusion, there are cases in which initial amplitude is lower than that considered as adequate by current literature but with well recognizable and stable EMG waveforms. How those cases should be approached and what should the surgeon's attitude be are a matter of discussion.

\section{Keywords: thyroid surgery, continuous nerve monitoring, vocal cord paralysis, vagus nerve intraoperative} monitoring, thyroid cancer

\section{INTRODUCTION}

Vocal cord paralysis (VCP) is the main complication of thyroidectomy, representing a lifethreatening event in case of bilateral damage.

VCP incidence varies greatly among different studies with an incidence ranging from 2.3 to $26 \%$ for transient forms and from 0.3 to $6 \%$ for permanent forms, with values increasing up to $14 \%$ in cases of revision surgery (1-3). 
Even if visual nerve identification represents the gold standard to prevent nerve injury, intraoperative neuromonitoring (IONM) can be considered as an additional technique for intraoperative nerve management and postoperative vocal cord function prognostication.

The use of IONM is recommended in all cases of total thyroidectomy, but especially in cases of thyroid cancer, revision thyroid surgery, or preoperative vocal cord dysfunction (4).

Continuous IONM (CIONM) allows real-time monitoring of nerve functional state, being able to recognize any potential nerve damage and to guide the surgeon in sudden corrective maneuvers aimed to preserve the functional nerve integrity.

Considering the progressive worldwide diffusion of the technique, the International Neural Monitoring Study Group (INMSG) issued state-of-the-art guidelines to uniform indication, technique, and electromyographic (EMG) waveform reading (5).

In this study we evaluated EMG waveforms related to the monitoring of 195 nerves, with particular focus on the amplitude of the recorded signals. Our evaluation led to some important issues that could have an impact on both signal interpretation and clinical practice.

\section{MATERIAL AND METHODS}

In this prospective single-institution study, we collected data from patients undergoing thyroid surgery with continuous intraoperative vagus nerve monitoring.

No case selection was conducted, and surgical indication was in accordance with International Guidelines $(6,7)$.All patients were informed about the use of CIONM and signed an informed consent.

Each patient underwent pre- and postoperative fiberoptic laryngoscopy; patients with preoperative cord paralysis were excluded from the study.

For each patient was used a short half-life non-depolarizing muscle relaxant (rocuronium at $0,5 \mathrm{mg} / \mathrm{kg}$ ). Train of four (TOF) stimulation was used for intraoperative neuromuscular transmission monitoring, considering the TOF \% as a reference parameter (ratio between the fourth and the first muscle response).

Vocal cord muscle depolarization detection was achieved by using an adhesive tube electrode (Dr. Langer Medical GmbH) placed 7-10 $\mathrm{mm}$ above the upper edge of the cuff; the electrode was wrapped around the endotracheal tube, covering the external lumen at $360^{\circ}$ and allowing to get thoroughly in contact with the vocal cords. Tube-positioning check was performed either by direct or video laryngoscopy, by evaluation of respiratory variation of the baseline, and by a so-called "tap test," even though it is an approximate method providing no quantitative data (8).

Surgery was made according to classic technique; we identified the vagus nerve in the neurovascular bundle, and before positioning the vagal probe, we checked neuromuscular circuit integrity by manual probe; visual identification of recurrent laryngeal nerve (RLN) was performed in all cases. Probe placement time and nerve monitoring did not significantly affect overall surgical time.

CIONM was used in all patients, regardless of vocal cord response amplitude initially measured, using Dr. Langer Medical GmbH's IONM system AVALANCHE ${ }^{\circledR}$ SI. This device offers seamless recurrent nerve monitoring via continuous vagus nerve stimulation (Saxophone electrode, Dr. Langer Medical GmbH), as well as the possibility of functional integrity check of motor nerves via intermittent stimulation by using a handheld stimulation probe (disposable monopolar probe, Dr. Langer Medical GmbH).

Stimulation is performed with a stimulus duration of $200 \mu \mathrm{s}$ and by a current of 1-2 mA, with 4 stimuli per second in intermittent stimulation and with 3 stimuli per second during continuous one.

Stimulation triggered MUAPs (Motor Unit Action Potential Duration) are filtered and amplified analogically and digitally. These high-resolution signals are presented to the end-user as a graphic and audible signal. Further to signal detection, this kind of signal processing offers the possibility to detect smallest signal changes immediately. The device automatically stores all signals in a database, allowing for a full postoperative signal review.

In our Institute this instrumental method is routinely used, and data analysis has not led any variation of patients' management intra- and postoperatively. Thereby, considering study characteristics, patients' enrollment, collection, and data analysis, for this study approval of ethics committee does not apply.

Dr. Langer Medical GmbH provides two stand-alone software tools: the "PC Viewer" application allows postoperative signal review, while the second tool allows the user to review all the stimulation data (time and date, stimulation current, amplitude, latency, stimulation probe used) in an MS Excel file.

Continuous variables were expressed as mean (M) and standard deviation (SD), categorical variables as number $(\mathrm{N})$ and percentage (\%). The Student 2-sample $t$ test and Pearson $\chi^{2}$ test were used to compare the differences between two groups for continuous and categorical variables, respectively.

Predictors of VCP were evaluated with logistic regression analysis, expressed as odds ratio, and 95\% confidence interval for continuous variables and with Cochran and Mantel-Haenszel odds ratio for categorical variables. Multivariate models were performed with logistic regression analysis to create adjustment for age, gender, type of thyroid disease, malignancy, and side of lesion.

A Receiving Operating Characteristic (ROC) curve analysis, which reported the area under the curve (AUC) with a 95\% confidence interval (CI), was performed to determine the diagnostic accuracy for VCP prediction and cut-off values; optimal sensitivity and specificity were calculated using Youden index. Significance was defined as a $\mathrm{p}$ value $<0.05$. All statistics were performed with SPSS version 26 (IBM Corporation). 


\section{RESULTS}

Over a 17-month period, from April 2018 to September 2019, we performed thyroid surgery with CIONM in 108 patients, 27 men (age range 31-79 years, mean 57,93 years) and 81 women (age range 19-82 years, mean 59,51 years). In 87 cases a total thyroidectomy and in 21 cases a loboistmectomy (14 right, 7 left) were performed, for a total of 195 dissected nerves (99 right, 96 left). Two nerves were excluded from the analysis: in one case, a worsening of a bradycardia already present at anesthetic induction occurred after placement of the vagal stimulation probe, which was removed, with restoring the previous values of heart rate; in another case we intraoperatively found a "nonrecurrent" recurrent laryngeal nerve, with cranial emergence at the site of the probe positioning and non-valid vagal signal. We therefore analyzed data related to 193 nerves.

In 71 cases surgery was performed for benign pathology (Multinodular Goiter, Adenoma, Graves-Basedow's disease, Thyroiditis). In 37 cases histology confirmed the malignant nature of the pathology: in 33 cases it was a papillary $\mathrm{Ca}$., in 1 case it was follicular Ca., and in 3 cases it was a medullary Ca. In three cases a central compartment lymph node dissection was performed; 10 patients underwent a lateral compartmentoriented selective neck dissection, according to International Guidelines, since there was a neoplastic lymph node involvement at the time of diagnosis (7).

With the exclusion of the case of intraoperative bradycardia, no cardiopulmonary complications occurred. In three cases we experienced an endotracheal tube displacement in caudocranial direction and had to put it back into the right position, with amplitude response retrieval. In three cases we had to interrupt the surgical procedure and did not complete the thyroidectomy due to the absence of vagal signal at the end of first thyroid lobe removal; in all three cases we observed a transient vocal cord palsy.

In our group of 193 nerves, we observed 11 cases of transient vocal cord palsy $(5,70 \%)$ and 4 cases of permanent palsy, in two of which there was a nerve neoplastic infiltration (2.07\%).

We divided nerves into three groups, according to the amplitude value of the signal obtained at the placement of the vagal probe. In 110 cases the initial amplitude of vagal stimulation response was $\geq 500 \mu \mathrm{V}$ (Group 1), and in 79 cases it was between 100 and $500 \mu \mathrm{V}$ (Group 2). The Group 3 includes four nerves who had an initial amplitude value $<100 \mu \mathrm{V}$ (Table 1).
No statistical differences between Group 1 and Group 2 were found in age (Group 1: $59 \pm 14$ years vs Group 2: $57 \pm 14$ years; $\mathrm{p}=0.234$ ), rate of malignancy (35 vs 37\%; $\mathrm{p}=0,759$ ), lesion size $>80 \mathrm{~cm}^{3}$ (24 vs 20\%; $\mathrm{p}=0,093$ ), or side (left side 47 vs $57 \%$; $\mathrm{p}=0.102)$; on the other hand, male gender was prevalent in Group 1 (80 vs 67\%: $\mathrm{p}=0.044)$.

Group 3 was excluded from statistical analysis due to the limited sample size.

\section{Prediction of VCP by Final Amplitude Absolute Value in Group 1 and Group 2}

ROC curve showed a high diagnostic accuracy of final amplitude absolute value in VCP detection in both Group 1 and Group 2, 89 and $86 \%$, respectively. In particular, the area under the ROC curve for Group 1 was $0.890(0.702-1.000 ; \mathrm{p}<0.0001)$ and for Group 2 was $0.861(0.702-1.000 ; \mathrm{p}<0.002)$.

\section{Prediction of VCP by Amplitude Variation in Group 1 and Group 2}

The data analysis of the two groups shows that an increase of VCP risk was associated with the progressive amplitude reduction during intervention in both groups (Group 1: $\mathrm{OR}=1.05, \mathrm{CI}=1.02-1.09, \mathrm{p}=0.001$; Group 2: $\mathrm{OR}=1.05, \mathrm{CI}=1.02-$ $1.08, \mathrm{p}=0.002$ ), corresponding to a mean increase of $5 \%$ of the relative risk of VCP per each percentage value of amplitude decrease in both groups (Figure 1).

The association between amplitude reduction and VCP risk remained independent even after multivariate analysis including age, gender, disease, and side of lesion in both groups (Group 1: $\mathrm{OR}=1.05, \mathrm{CI}=1.02-1.09, \mathrm{p}=0.003$; Group 2: $\mathrm{OR}=1.05, \mathrm{CI}=1.01-$ $1.09, \mathrm{p}=0.005)$.

ROC curve showed a high diagnostic accuracy of amplitude reduction in VCP detection in both Group 1 and Group 2, 88 and $92 \%$, respectively. In particular, the area under the ROC curve for Group 1 was $0.877(0.682-1.000 ; \mathrm{p}<0.0001)$ and for Group 2 was 0.919 (0.833-1.000; $\mathrm{p}<0.0001)$ (Figure 2).

Using ROC curves to determine the diagnostic accuracy of VCP, cut-off values for amplitude reduction (calculated using Youden index) with optimal sensitivity and specificity were $-77 \%$ in Group $1(\geq 500 \mu \mathrm{V})$ and $-15 \%$ in Group 2 (between 100 and $500 \mu \mathrm{V})$. The area under the ROC curve for amplitude reduction (Group 1, cut-off 77) was 0.908 (95\%CI: 0.770-1.000; $\mathrm{p}<0.0001)$ corresponding to sensitivity $=87 \%$ and

TABLE 1 | Main features of EMG signals for Groups 1, 2, and 3. In Group 1 one nerve had A1=A2.

\begin{tabular}{|c|c|c|c|c|c|c|c|c|c|}
\hline & $\begin{array}{l}\text { Number } \\
\text { of nerves }\end{array}$ & $\begin{array}{c}\text { Mean initial } \\
\text { amplitude }[\mu \mathrm{V}]\end{array}$ & $\begin{array}{c}\text { Mean final } \\
\text { amplitude } \\
{[\mu \mathrm{V}]}\end{array}$ & $\begin{array}{l}\text { Number of } \\
\text { nerves with } \\
\text { amplitude } \\
\text { decrease }\end{array}$ & $\begin{array}{l}\text { Number of } \\
\text { nerves with } \\
\text { amplitude } \\
\text { increase }\end{array}$ & $\begin{array}{c}\text { Mean amplitude } \\
\text { decrease (\%) }\end{array}$ & $\begin{array}{c}\text { Mean amplitude } \\
\text { increase (\%) }\end{array}$ & $\begin{array}{c}\text { Early postoperative } \\
\text { VCP }\end{array}$ & $\begin{array}{c}\text { Permanent } \\
\text { VCP }\end{array}$ \\
\hline Group & 110 & 895 & 670 & 77 & 32 & $44,59 \%$ & $36,85 \%$ & 5 & 3 \\
\hline $\begin{array}{l}\text { Group } \\
2\end{array}$ & 79 & 306 & 322 & 43 & 36 & $34,42 \%$ & $75,24 \%$ & 6 & 1 \\
\hline Group & 4 & 77 & 71 & 3 & 1 & $23,56 \%$ & $70 \%$ & 0 & 0 \\
\hline
\end{tabular}



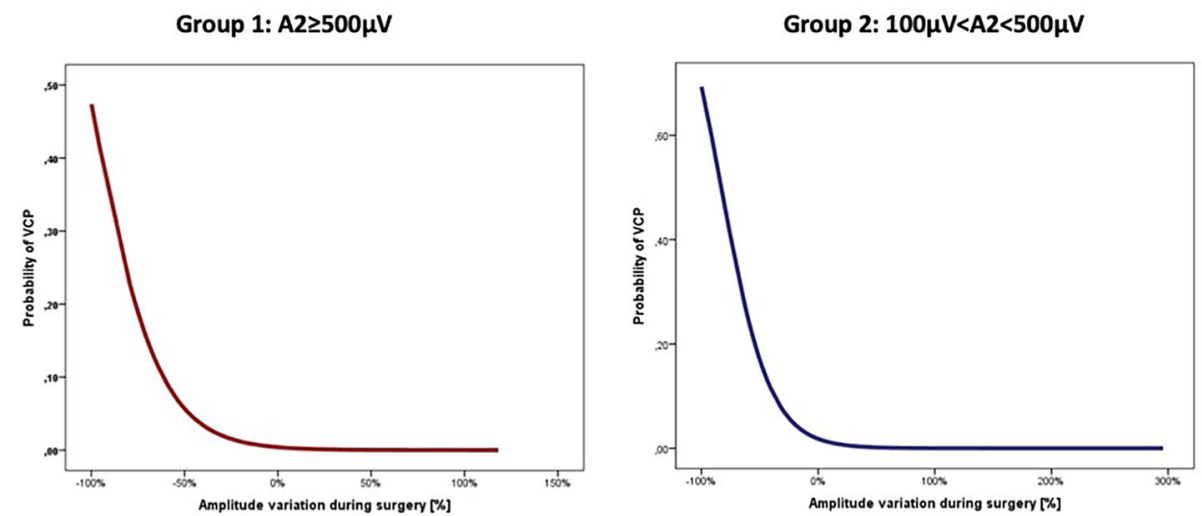

FIGURE 1 | Linear correlation between probability of VCP and amplitude variation during surgery.
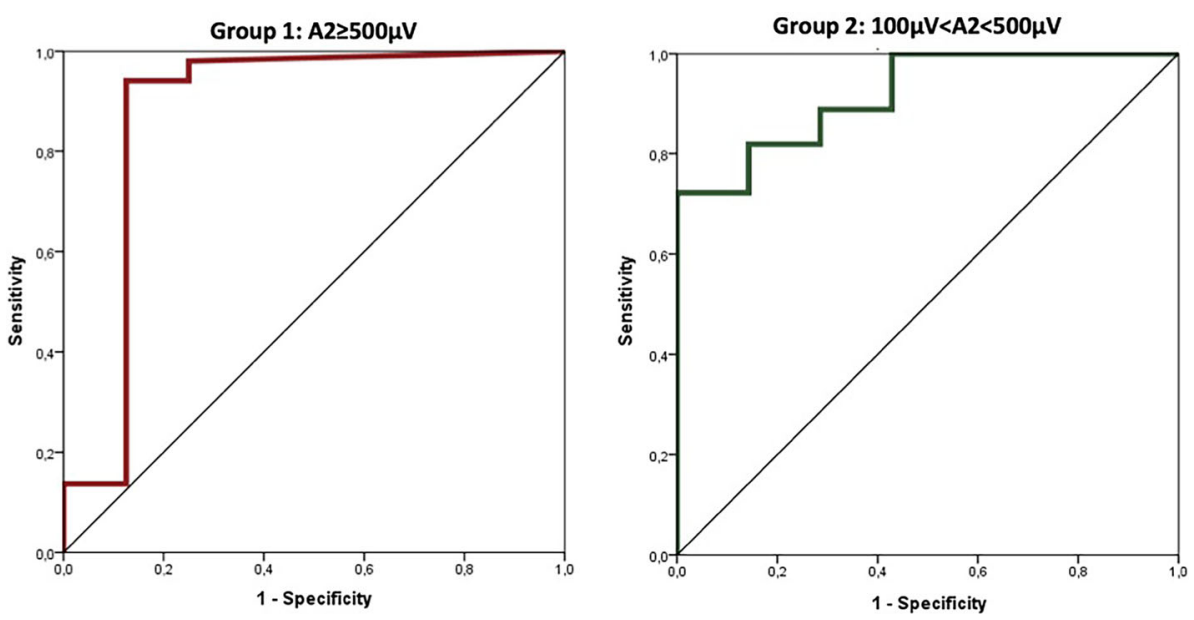

FIGURE 2 | ROC curves analysis for diagnostic accuracy of amplitude reduction in VCP detection.

specificity $=94 \%$. Similarly, the area under the ROC curve for amplitude reduction (Group 2, cut-off 15) was 0.797 (95\%CI: $0.632-0.961 ; \mathrm{p}=0.010)$ corresponding to sensitivity $=86 \%$ and specificity $=74 \%$ (Figure 3 ).

\section{Group 3}

Interestingly in four cases, despite having ensured the correct positioning of endotracheal tube, the absence of neuromuscular blocking agents, and the functionality of the monitoring system, the EMG signals showed an amplitude $<100 \mu \mathrm{V}$ since the positioning of the probe and for the entire duration of the monitoring. In none of these cases we experienced loss of a recognizable signal with defined amplitude and latency and observed postoperative cordal paralysis. Table 2 shows the main features of EMG signals for these nerves (Table 2). In Figures 4-6 we show an explicative case in which the right vagus nerve shows an amplitude value lower than $100 \mu \mathrm{V}$ for the whole surgery, despite a normal postoperative cordal motility.

\section{DISCUSSION}

Visual identification of RLN still represents the gold standard for prevention of recurrential damages. However, nerve identification could be difficult due to several anatomical variables, particular clinical pictures, or revision surgery (9). Moreover, the nerve anatomical integrity may not correspond to the functional integrity. The authors agree that in most cases (75-83\%) the RLN damage is caused by a traction injury, particularly in correspondence with the Berry's ligament; other causes of nerve damage include thermal, compressive, clamping and ligature 

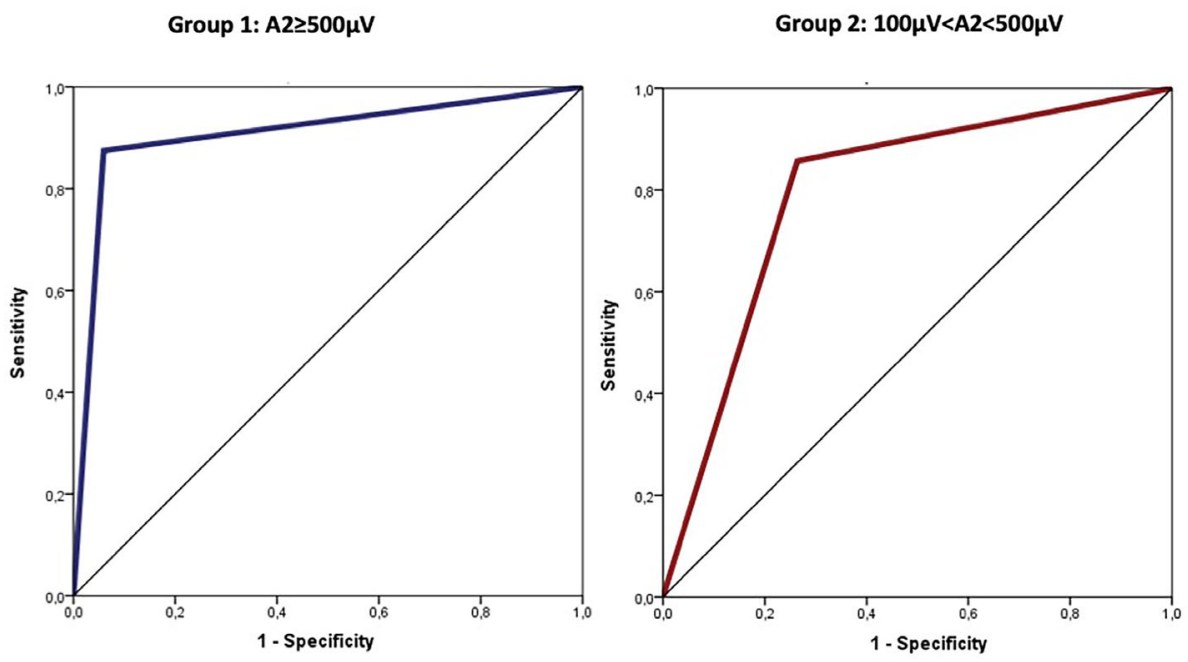

FIGURE 3 | Cut-off values for amplitude reduction with optimal sensitivity and specificity were $-77 \%$ in group 1 ( $\geq 500 \mu$ V) and $-15 \%$ in group 2 (between 100 and $500 \mu$ V).

TABLE 2 | Main characteristics of waveform with amplitude $<100 \mu \mathrm{V}$.

\begin{tabular}{|c|c|c|c|c|c|c|c|c|}
\hline PATHOLOGY & $\begin{array}{c}\mathrm{A1} \\
{[\mu \mathrm{V}]}\end{array}$ & $\begin{array}{r}\mathrm{A} 2 \\
{[\mu \mathrm{V}]}\end{array}$ & $\begin{array}{c}\text { Amplitude } \\
\text { decrease [\%] }\end{array}$ & $\begin{array}{c}\text { Amplitude } \\
\text { increase [\%] }\end{array}$ & VCP & $\begin{array}{c}\% \text { single event: decrease } \\
\text { amplitude of } 50 \%\end{array}$ & $\begin{array}{c}\% \text { single event: latency } \\
\text { increase of } 10 \%\end{array}$ & $\begin{array}{c}\text { Max consecutive time of } \\
\text { both events (s) }\end{array}$ \\
\hline Papillary ca & 82 & 64 & 21,95 & - & no & 12,54 & 30,3 & 7 \\
\hline Benign & 91 & 71 & 21,98 & - & no & 23,52 & 4,95 & 7 \\
\hline Benign & 86 & 63 & 26,74 & - & no & 1,73 & 11,5 & 8 \\
\hline Benign & 50 & 85 & - & 70,00 & no & 0 & 26,48 & - \\
\hline
\end{tabular}

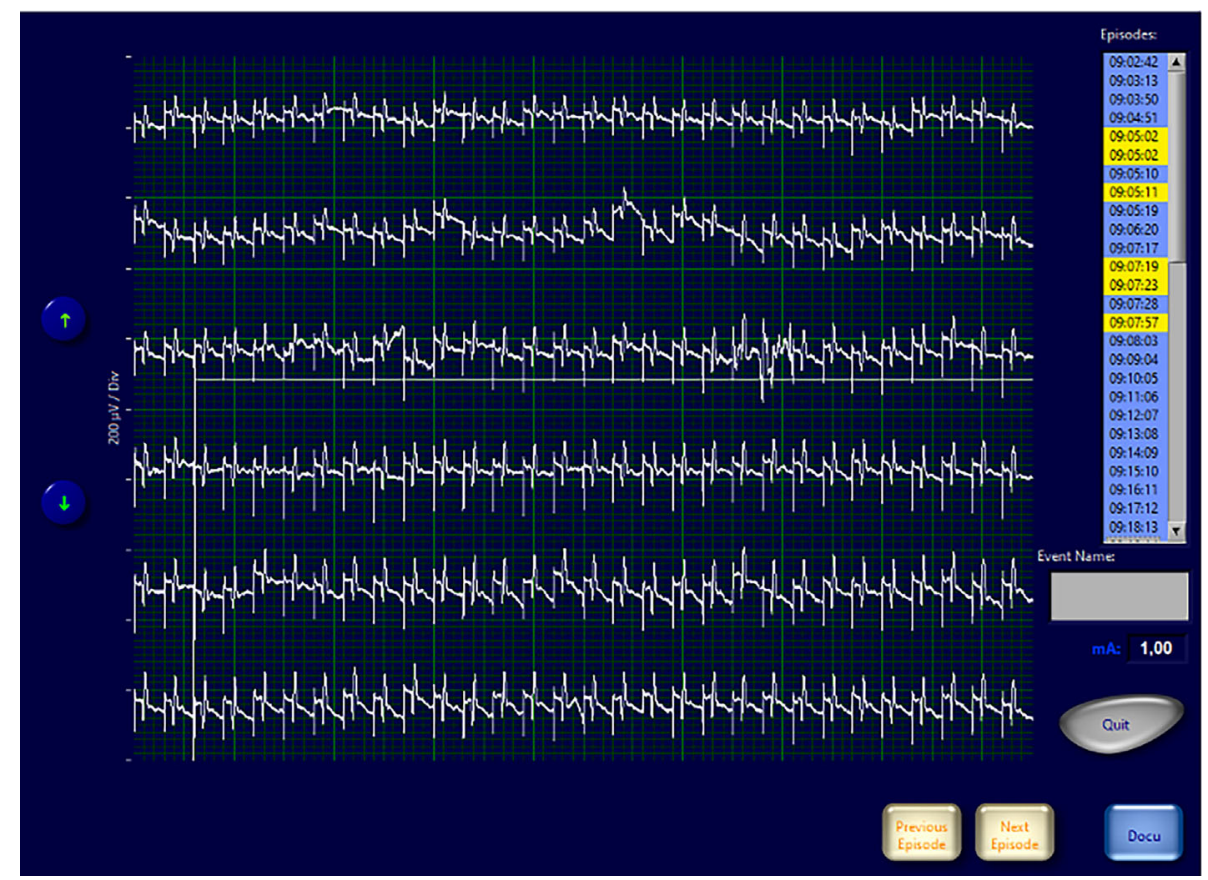

FIGURE 4 | EMG frame that shows EMG waveforms during continuous vagal stimulation with amplitude $<100 \mu \mathrm{V}$ in a patient with normal pre- and postoperative vocal cord function. 

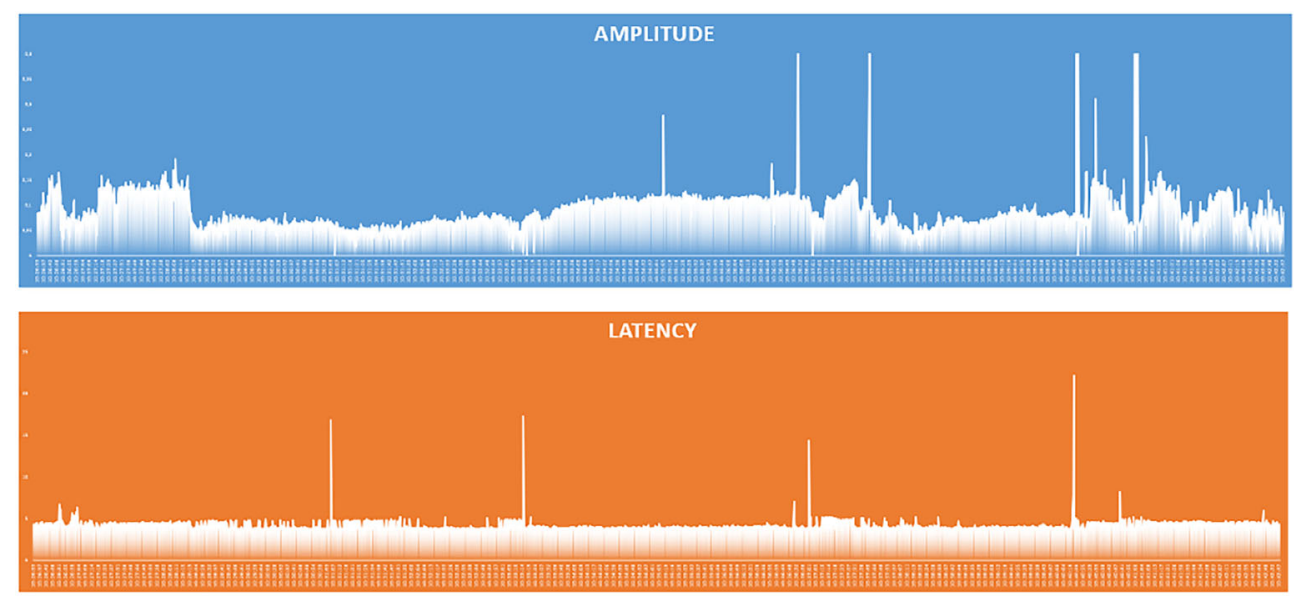

FIGURE 5 | Graphical representation of amplitude and latency values of the responses of the continuous vagal stimulation in a patient with amplitude <100 $\mu \mathrm{V}$ and normal pre- and postoperative vocal cord function.

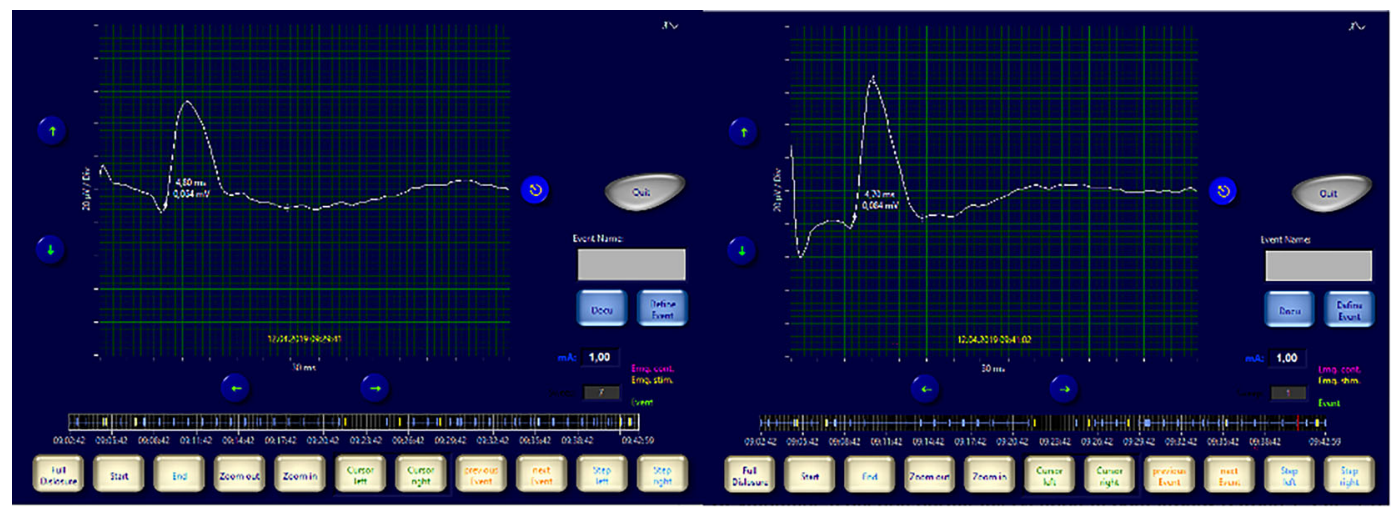

FIGURE 6 | Right vagus nerve signal (Amplitude <100 $\mu$ V): before and after lobectomy.

damage, entrapment, suction-related injury, and transection (10-12). A study by Dionigi et al. showed that in a group of 281 nerve injuries, only $14 \%$ of the damages would have been identified intraoperatively with direct visualization and without nerve functional monitoring (13). In the last years, IONM during thyroid surgery has gained worldwide acceptance as additional aid for visual RLN identification. According to literature, the main applications of IONM are identification of the RLN, aid in dissection, lesion site identification, and postoperative neural function prognostication (8). Although some reviewers consider the advantages linked to intermittent IONM as limited, especially for damage prevention, IONM is employed worldwide, as recommended by the American Head and Neck Society, especially in all thyroid cancer cases and particularly in those complicated by pre-surgery RNL paralysis and in revision surgeries (14).CIONM represents instead an important evolution that is progressively showing a superiority over intermittent monitoring in preventing vocal cord palsy (15). The periodic automatic electrical stimulation of the vagus nerve with an intensity of 1-2 $\mathrm{mA}$ causes the contraction of vocal cord muscles, whose activity is converted into an acoustic and visual signal; the surface electrode in contact with the vocal cords records the electromyographic waveform during the whole intraoperative stimulation. The real-time monitoring of the whole vagusrecurrent circuit during dissection allows immediate assessment of imminent damage and consequent corrective surgical maneuvers, thanks to early acknowledgment of variation in the electromyographic waveform. As known, the response signal to the vagal stimulus is represented by a biphasic wave corresponding to the action potential of the motor unit of the ipsilateral thyroarytenoid muscles. Each wave is defined by two parameters: the amplitude, which can vary significantly from subject to subject and is correlated with the number of muscle fibers that participate in the depolarization during stimulation, and the latency, which corresponds to the time elapsed from stimulation to the first peak of the muscle response. After probe 
positioning, a reference EMG response, defined as Baseline, is acquired. During the whole monitoring, the changes in EMG response are therefore analyzed and compared to baseline. Due to relatively recent introduction of CIONM and its limited diffusion, a standardization of waveform interpretation is still necessary, despite numerous studies attempting to identify the correlation between neurophysiopathological data of nerve stimulation with the clinical data of cordal functionality. In 2018, Schneider et al., on the basis of the experiences of the working group and of the different publications previously reported, tried to formulate stateof-the art guidelines, defining reference parameters. From an empirical parallelism with the monitoring systems of other peripheral nerves, a signal with an initial amplitude equal to or greater than $500 \mu \mathrm{V}$ was defined as adequate. Moreover, as reported by the INMSG, intraoperative LOS (Loss of signal) is defined as the loss of a recognizable EMG signal with curve amplitude below the $100 \mu \mathrm{V}$ threshold $(5,8)$. Potentially harmful adverse events are identified by quantitative amplitude and latency variations characterizing the reference signal. Variations of the EMG signal can be single (decrease of amplitude or increase of latency) or combined (decrease of amplitude and increase of latency). A joint reduction $>50 \%$ in amplitude and an increase $>10 \%$ in latency lasting $40-60 \mathrm{~s}$ are related to a high risk of vocal cord paralysis. The authors suggest that the final wave amplitude value $>250 \mu \mathrm{V}$ correlates with the highest PPV and NPV results (75-99\%); a final EMG signal with an amplitude $>250 \mu \mathrm{V}$, which represents at least $50 \%$ of the baseline value, is strongly indicative of normal postoperative cordal function $(5,8)$. In our personal experience we analyzed the plots of 193 nerves. During each monitoring, the correct positioning of the endotracheal tube, the standardized use of short-acting muscle relaxants, and the functional integrity of the circuit connections with the generator were peremptorily ensured. In 110 cases, the acquired EMG signals met the criteria established by INMSG guidelines, with an initial amplitude value of at least $500 \mu \mathrm{V}$. In the other 83 cases, however, we weren't able to obtain such an initial amplitude value, despite having ensured the correct positioning of endotracheal tube, the absence of neuromuscular blocking agents, and the functionality of the monitoring system. Nevertheless, we decided to perform intraoperative neuromonitoring in these cases, as the detected EMG waveforms were well recognizable and stable. Furthermore, in four cases the EMG signals showed an amplitude $<100 \mu \mathrm{V}$ since probe positioning and for the entire duration of the monitoring, despite a physiological cordal motility both preoperatively and postoperatively. The data analysis showed that an increase of VCP risk was associated with the progressive amplitude reduction during intervention in both groups (Group 1: initial stimulation amplitude $\geq 500 \mu \mathrm{V}$; Group 2: initial stimulation amplitude between 100 and $500 \mu \mathrm{V}$ ), corresponding to a mean increase of $5 \%$ of the relative risk of VCP per each percentage value of amplitude decrease. Furthermore, it allowed us to determine two cut-off values for amplitude reduction with optimal sensitivity and specificity: $-77 \%$ in Group 1 and $-15 \%$ in Group 2. The comprehensive evaluation of the EMG waveforms led to several questions, which still need to be answered:
- How should the surgeon approach a situation in which the initial response to vagal stimulation has an amplitude lower than $500 \mu \mathrm{V}$ ?

- Would it be plausible to perform continuous neuromonitoring in such situations?

- Should the resulting EMG waveforms be considered reliable, and should the surgeon trust them to perform intraoperative corrective maneuvers when the amplitude decreases?

- Can a statistical analysis be used to define specific threshold values for the neuromonitoring when the initial response has an amplitude lower than $500 \mu \mathrm{V}$ ?

- How to approach those cases in which the initial response has a well recognizable waveform with an amplitude lower than $100 \mu \mathrm{V}$, which is considered to be LOS as per INMSG guidelines?

Considering intra and inter-subject variability of nerve transmission, the use of an amplitude cut-off value $\geq 500 \mu \mathrm{V}$ could be too restrictive. In our experience, waveforms with baseline amplitude $<500 \mu \mathrm{V}$ may be considered equally adequate, as shown in overlapping results in comparison groups. Setting the alarm for a reduction of $77 \%$ in patients with initial amplitude $\geq 500 \mu \mathrm{V}$ and of $15 \%$ for those $<500 \mu \mathrm{V}$ could make monitoring safe and an effective aid for surgeon also in these cases.

\section{CONCLUSIONS}

Intraoperative neuromonitoring represents a safe and effective method for leading the surgeon during dissection and identification of recurrent nerve; it is universally accepted as a method capable of intraoperatively assessing the nerve functional integrity and preventing bilateral cordal paralysis in total thyroidectomies.

According to a recent multicentric retrospective clinical trial, continuous nerve monitoring compared to intermittent one shows a better predictivity of vocal cord paralysis (15). While the costs of the procedure need to be considered, it is clear how the cost/effectiveness leads to the use of neuromonitoring, especially in selected cases.

Therefore, the surgeon must have clear elements to interpret correctly EMG plots and to use CIONM as a real aid in surgical practice. The literature shows unique data interpretations when the nerve responses have an initial amplitude $\geq 500 \mu \mathrm{V}$.

Our experience showed that there are cases in which initial amplitude is lower than that considered as adequate by current literature but with well recognizable and stable EMG waveforms.

How those cases should be approached and what should the surgeon's attitude be are a matter of discussion; further studies on larger populations are required to address these issues.

\section{DATA AVAILABILITY STATEMENT}

The raw data supporting the conclusions of this article will be made available by the authors, without undue reservation. 


\section{ETHICS STATEMENT}

Ethical approval was not provided for this study on human participants because, based on the characteristics of the study, the Medical Management of the Hospital of Pordenone did not consider that the study needed approval. The patients/ participants provided their written informed consent to participate in this study.

\section{REFERENCES}

1. Jeannon JP, Orabi AA, Bruch GA, Abdalsalam HA, Simo R. Diagnosis of Recurrent Laryngeal Nerve Palsy After Thyroidectomy: A Systematic Review. Int J Clin Pract (2009) 63(4):624-9. doi: 10.1111/j.1742-1241.2008.01875.x

2. Christou N, Mathonnet M. Complications After Total Thyroidectomy. J Visc Surg (2013) 150(4):249-56. doi: 10.1016/j.jviscsurg.2013.04.003

3. Joliat GR, Guarnero V, Demartines N, Schweizer V, Matter M. Recurrent Laryngeal Nerve Injury After Thyroid and Parathyroid Surgery: Incidence and Postoperative Evolution Assessment. Med (Baltimore) (2017) 96 (17):6674. doi: 10.1097/MD.0000000000006674

4. Terris DJ, Snyder S, Carneiro-Pla D, Inabnet WB 3rd, Kandil E, Orloff L, et al. American Thyroid Association Statement on Outpatient Thyroidectomy. Thyroid (2013) 23(10):1193-202. doi: 10.1089/thy.2013.0049

5. Schneider R, Randolph GW, Dionigi G, Wu CW, Barczynski M, Chiang FY, et al. International Neural Monitoring Study Group Guideline 2018 Part I: Staging Bilateral Thyroid Surgery With Monitoring Loss of Signal. Laryngoscope (2018) 128 Suppl 3:S1-17. doi: 10.1002/lary.27359

6. Haugen BR, Alexander EK, Bible KC, Doherty GM, Mandel SJ, Nikiforov YE, et al. 2015 American Thyroid Association Management Guidelines for Adult Patients With Thyroid Nodules and Differentiated Thyroid Cancer: The American Thyroid Association Guidelines Task Force on Thyroid Nodules and Differentiated Thyroid Cancer. Thyroid (2016) 26(1):1-133. doi: 10.1089/ thy.2015.0020

7. Patel KN, Yip L, Lubitz CC, Grubbs EG, Miller BS, Shen W, et al. The American Association of Endocrine Surgeons Guidelines Forthe Definitive Surgical Management of Thyroid Disease in Adults. Ann Surg (2020) 271(3): e21-93. doi: 10.1097/SLA.0000000000003580

8. Randolph GW, Dralle H, International Intraoperative Monitoring Study Group, Abdullah H, Barczynski M, Bellantone R, et al. Electrophysiologic Recurrent Laryngeal Nerve Monitoring During Thyroid and Parathyroid Surgery: Internationalstandards Guideline Statement. Laryngoscope (2011) 121 Suppl 1:S1-16. doi: 10.1002/lary.21119

9. Steurer M, Passler C, Denk DM, Schneider B, Niederle B, Bigenzahn W. Advantages of Recurrent Laryngeal Nerve Identification in Thyroidectomy and Parathyroidectomy and the Importance of Preoperative and Postoperative Laryngoscopic Examination in More Than 1000 Nerves at Risk. Laryngoscope (2002) 112:124-33. doi: 10.1097/00005537-200201000-00022

10. Phelan E, Schneider R, Lorenz K, Dralle H, Kamani D, Potenza A, et al. Continuous Vagal IONM Prevents Recurrent Laryngeal Nerve Paralysis by

\section{AUTHOR CONTRIBUTIONS}

All authors listed have made a substantial, direct, and intellectual contribution to the work, and approved it for publication.

\section{FUNDING}

The funding for the publication comes from SEDA-SPA.

Revealing Initial EMG Changes of Impending Neuropraxic Injury: A Prospective, Multicenter Study. Laryngoscope (2014) 124:1498-505. doi: 10.1002/lary.24550

11. Schneider R, Lamade W, Hermann M, Goretzki P, Timmermann W, Hauss J, et al. Continuous Intraoperative Neuromonitoring of the Recurrent Laryngeal Nerve in Thyroid Surgery (CIONM): Where Are We Now? An Update to the European Symposium of Continuous Neuromonitoring in Thyroid Surgery. Zentralbl Chir (2012) 137:88-90. doi: 10.1055/s-0030-1262697

12. Chiang FY, Lu IC, Kuo WR, Lee KW, Chang NC, Wu CW. The Mechanism of Recurrent Laryngeal Nerve Injury During Thyroid Surgery-the Application of Intraoperative Neuromonitoring. Surgery (2008) 143:743-9. doi: 10.1016/ j.surg.2008.02.006

13. Dionigi G, Wu CW, Kim HY, Rausei S, Boni L, Chiang FY. Severity of Recurrent Laryngeal Nerve Injuries in Thyroid Surgery. World J Surg (2016) 40:1373-81. doi: 10.1007/s00268-016-3415-3

14. Ark N, Zemo S, Nolen D, Holsinger FC, Weber RS. Management of Locally Invasive Well-Differentiated Thyroid Cancer. Surg Oncol Clin N Am (2008) 17 (1):145-55. doi: 10.1016/j.soc.2007.10.009

15. Schneider R, Machens A, Sekulla C, Lorenz K, Elwerr M, Dralle H. Superiority of Continuous Over Intermittent Intraoperative Nerve Monitoring in Preventing Vocal Cord Palsy. J Surg (2020) 108(5):566-73. doi: 10.1002/ bjs. 11901

Conflict of Interest: The authors declare that the research was conducted in the absence of any commercial or financial relationships that could be construed as a potential conflict of interest.

Publisher's Note: All claims expressed in this article are solely those of the authors and do not necessarily represent those of their affiliated organizations, or those of the publisher, the editors and the reviewers. Any product that may be evaluated in this article, or claim that may be made by its manufacturer, is not guaranteed or endorsed by the publisher.

Copyright (c) 2021 Mazzone, Esposito and Giacomarra. This is an open-access article distributed under the terms of the Creative Commons Attribution License (CC BY). The use, distribution or reproduction in other forums is permitted, provided the original author(s) and the copyright owner(s) are credited and that the original publication in this journal is cited, in accordance with accepted academic practice. No use, distribution or reproduction is permitted which does not comply with these terms. 